LPPM UNIHAZ $\quad \begin{gathered}\text { ABDIHAZ: Jurnal Ilmiah Pengabdian pada Masyarakat } \\ \text { https://journals.unihaz.ac.id/index.php/abdihaz }\end{gathered}$

\title{
Program Pendampingan Kemasan Pangan bagi Tenant melalui Pusat Pengembangan Wirausaha Bioindustri
}

\section{Food Packaging Assistance Program for Tenants through the Bioindustry Entrepreneur Development Center}

\author{
Hermawan Seftiono ${ }^{1 *}$, Maulidian ${ }^{2}$, Inanpi Hidayati Sumiasih ${ }^{3}$, Mutiara Dewi Puspitawati $^{3}$ \\ ${ }^{1}$ Prodi Ilmu dan Teknologi Pangan, Universitas Trilogi, Jl. Kampus Universitas Trilogi No 1, Kalibata, Jakarta, \\ Indonesia \\ ${ }^{2}$ Prodi Agribisnis, Universitas Trilogi, Jl. Kampus Universitas Trilogi No 1, Kalibata, Jakarta, Indonesia \\ ${ }^{3}$ Prodi Agroekoteknologi, Universitas Trilogi, Jl. Kampus Universitas Trilogi No 1, Kalibata, Jakarta, Indonesia
}

\begin{tabular}{|c|c|}
\hline Info Artikel & ABSTRAK \\
\hline $\begin{array}{l}\text { Diterima } 27 \text { Oktober } 2020 \\
\text { Ditelaah } 12 \text { Juni } 2021 \\
\text { Disetujui 05 Desember } 2021 \\
\text { Tersedia daring } 30 \text { Desember } \\
2021\end{array}$ & $\begin{array}{l}\text { Kemasan suatu produk sangat penting terutama dalam menarik minat } \\
\text { konsumen. Oleh karena itu, kemasan perlu disesuaikan dengan segmen } \\
\text { pasar karena selera konsumen terhadap produk terlihat dari kemasan. } \\
\text { Umumnya, para tenant sudah memiliki kemasan walaupun sangat } \\
\text { sederhana hanya berisi nama produk. Program pendampingan ini akan } \\
\text { meningkatkan keperdulian para tenant dalam membuat kemasan yang } \\
\text { sesuai dengan aturan pelabelan produk pangan. Peserta kegiatan adalah } 12\end{array}$ \\
\hline $\begin{array}{l}\text { *Penulis untuk korespondensi } \\
\text { hermawan seftiono@trilogi.ac.id }\end{array}$ & $\begin{array}{l}\text { tenant. Tahapan dalam kegiatan pengabdian kepada masyarakat meliputi } \\
\text { pemberian materi tentang kemasan pangan, presentasi beberapa contoh }\end{array}$ \\
\hline $\begin{array}{l}\text { Kata Kunci: } \\
\text { Desain, Kuliner, Label, } \\
\text { Teknososioprenur, Tenant }\end{array}$ & $\begin{array}{l}\text { kemasan dan pendampingan serta konsultasi tenant terhadap kemasan } \\
\text { pangan bagi produk. Kegiatan pendampingan ini memberikan manfaat bagi } \\
\text { para tenant berdasarkan hasil evaluasi. Sekitar } 80 \% \text { tenant mengalami } \\
\text { perubahan tekait kemasan baik berupa desain maupun informasi yang } \\
\text { diperlukan pada kemasan. }\end{array}$ \\
\hline
\end{tabular}
diperlukan pada kemasan.

Keywords:

Culinary, Design, Label,

Technosociopreneur, Tenant

\begin{abstract}
Packaging is very important, especially on attracting consumer interest, so it needs to be adjusted based on market segments, because consumer tastes of products can be seen from the packaging. Generally, tenants already have packaging, but it was very simple, just mention the name of the product. Therefore, this mentoring program would increase awareness of tenants to make packaging based on labelling regulation for food products. The stages on this community service activity included provision of food packaging, presenting some packaging samples and assisting also giving consultation for tenant about food product packaging. This mentoring activity provided many benefits for tenants. There were 12 tenants participated on this activity. About $80 \%$ of participants got improve for their package, on design also information which required on the packaging.
\end{abstract} ISSN 2685-0354 (Media Online). Diterbitkan oleh Universitas Prof. Dr. Hazairin, SH. Ini merupakan jurnal bebas akses di bawah lisensi Creative Commons Atribution 4.0 International.

\section{PENDAHULUAN}

Tren bagi anak muda untuk berbisnis mulai marak beberapa tahun ini. Indikasinya adalah munculnya berbagai macam start up atau tenant baik kegiatan di luar maupun di dalam kampus. 
Berbagai start up yang muncul dan sukses diIndonesia seperti kopi kenangan, janji jiwa, fore coffee, upnormal dan lain-lain. Perkembangan pangan khususnya dibidang kuliner memunculkan banyak ide dari anak muda sehingga banyak terdapat café atau rintisan makanan online. Berkembangnya industri kuliner ini tidak terlepas dengan adanya electronic word of mouth terhadap loyalitas pelanggan yang menggunakan Instagram (Jesslyn \& Loisa, 2019)

Universitas Trilogi terutama di tingkat Fakultas Bioindustri memiliki inkubator yang bernama program Pusat Pengembangan Kapasitas Wirausaha Bioindustri (PPKWB) yang setiap tahunnya menghasilkan belasan tenant. Kegiatan ini telah dimulai dari tahun 2019 dengan 26 tenant yang berpartisipasi dan dihasilkan 12 tenant terpilih (Maulidian, 2019). Hal ini dalam upaya mencapai visi misi universitas terkait teknososiopreneur sehingga dihasilkan wirausaha yang dapat memanfaatkan teknologi serta berperan dalam meningkatkan kesejahteraan lingkungannya.

Berbagai kegiatan diberikan dalam upaya pendampingan agar para tenat dapat memulai ide usahanya. Salah satu kegiatan yang dilakukan adalah pendampingan terkait kemasan pada produk. Kemasan sangat penting terutama dalam menarik minat konsumen sehingga perlu disesuaikan segmen pasar, karena selera konsumen akan produk terlihat dari kemasan (Kodir, 2020). Umumnya para tenant sudah memiliki kemasan walaupun sangat sederhana hanya label berupa nama produk. Oleh karena itu program pendampingan kemasan pangan ini akan meningkatkan kepedulian para tenant dalam membuat kemasan yang sesuai dengan aturan pelabelan produk pangan. Dengan adanya program pendampingan kemasan ini diharapkan ada peningkatan penjualan produk, karena konsumen menjadi lebih yakin dan merasa aman memberi produk tersebut.

\section{METODE}

Kegiatan ini berasal dari program pusat pengembangan wirausaha bioindustri (PPKWB) yang didanai oleh kemenristekbrin. Kegiatan berupa kelas entrepreneur di era kenormalan baru. Kegiatan dilaksanakan secara 2 tahap, tahap pertama berupa kelas online menggunakan zoom yang dihadiri oleh 12 usaha tenant. Kelas online ini meliputi pemberian materi tentang kemasan pangan, presentasi beberapa contoh kemasan yang dilaksankan pada hari rabu 22 juli 2020. Tahap selanjutnya berupa konsultasi bebrapa tenant terhadap kemasan pangan dari bulan Juli sampai September 2020.

\section{HASIL DAN PEMBAHASAN}

Kegiatan PPKWB pada tahun 2020 bertepatan dengan kondisi wabah covid 19 yang melanda di Indonesia. Oleh karena itu pada tahun 2020 kegiatan lebih dilaksanakan secara online. Tema kegiatan yaitu Teknososiopreneur di era kenormalan baru. Kegiatan kelas online ini diikuti oleh 12 tenant diantaranya Dalcomy, Vegefish, Albedo Candy, Burgernesi, Roti Karkus, yubi Nugget, Pyong Kitchen, Indorice, Bubblely Bob's, Fancis Jam, Rainbowlu, Saritem dengan jumlah peserta 26 orang (Gambar 1).

Materi yang disampaikan dalam kegiatan pelatihan online meliputi peranan kemasan dalam membantu penjualan karena kemasan sebagai silent salesmen sehingga informasi-informasi yang ada pada kemasan akan membantu konsumen dalam memutuskan membeli produk tersebut. Menurut Nugrahani (2015) informasi yang disampaikan ke konsumen harus bersifat instan dan langsung serta dapat mengikat secara emosional. 
Sebagai contoh pada kemasan produk keripik, kemasan yang hanya menempelkan sticker dengan printing pada kemasan akan mempengaruhi konsumen dalam membeli produk tersebut. Konsumen ketika membeli produk yang dikemas secara printing akan memperoleh banyak informasi yang dibutuhkan konsumen. Informasi yang lengkap pada kemasan akan memberikan keyakinan bagi calon pembeli untuk membeli produk tersebut (Mukhtar, 2015).

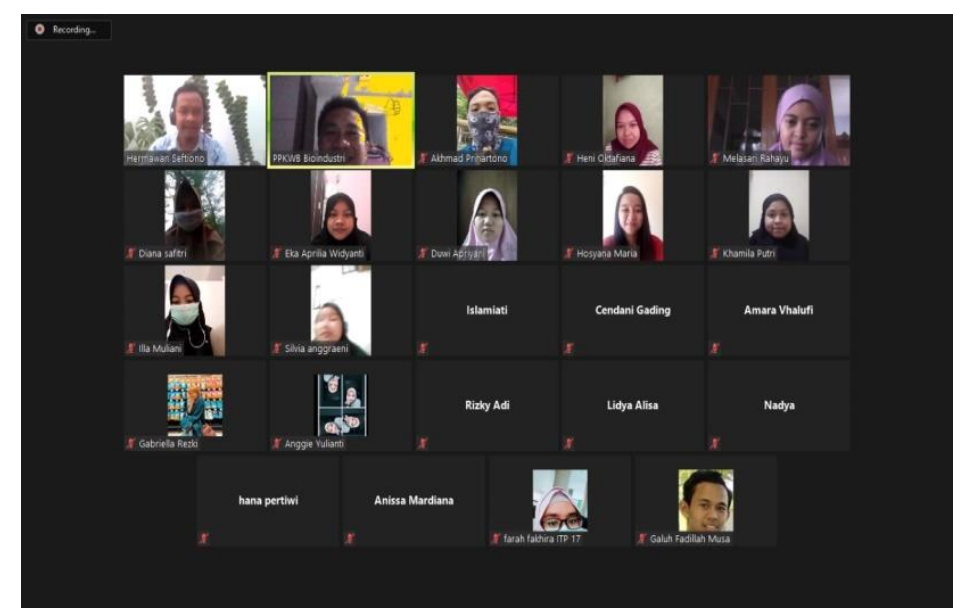

Gambar 1 Kegiatan zoom tentang kemasan dan industry kecil dan menengah (IKM) Pangan

Jenis kemasan akan berpengaruh tekait nilai jual, misalnya pada produk air minum dalam kemasan (AMDK) yang menggunakan kemasan plastik dan kemasan gelas. keputusan konsumen membeli produk karena didorong dengan kemasan yang bersih serta kesesuaian produk AMDK merek Aqua atas kualitas yang telah sesuai dengan standar yang ditetapkan (Ningsih et al., 2015)

AMDK yang menggunakan kemasan kaca akan memberikan kesan mewah, selain itu memiliki keunggulan lain seperti aman dari migrasi yang berasal dari kemasan, bersifat kaku sehingga menjadi penghalang kontaminasi dari luar serta dapat diadur ulang. AMDK yang menggunakan kemasan kaca akan memiliki nilai jual yang lebih tinggi bila dibandingkan dengan kemasan yang menggunakan kemasan plastik (Gambar 2).

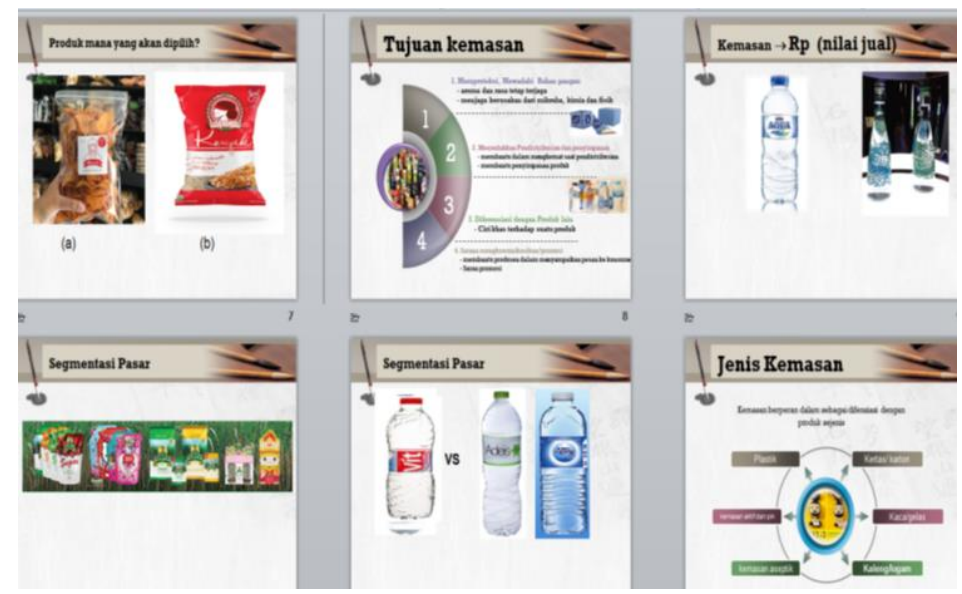

Gambar 2 Materi tentang kemasan dan IKM Pangan

Produsen akan melakukan segmentasi berdasarkan kemasan yang digunakan. Pada produk AMDK dengan menggunakan jenis kemasan yaitu kemasan plastik atau kemasan gelas. Produk gula melakukan segmentasi dari jenis kemasan atau desain kemasan tersebut. Kemasan gula tersebut ada yang segmen bagi dewasa serta ada bagi anak-anak. Segmen dewasa dengan 
menggunakan gambar buah pada kemasan sedangkan untuk anak-anak pada kemasan terdapat tokoh animasi hello kitty. Penambahan gambar berupa animasi dan pemilihan warna kontras membuat kemasan terlihat lebih menarik (Pulungan, 2019). Selain itu segmentasi dengan menggunakan jenis kemsannya yaitu kemasan kiloan dengan plastik pack sedangkan untuk sachet memakai sachet dari kertas (Gambar 2).

Informasi lain yang disampaikan pada kegiatan pelatihan yaitu Peraturan Badan Pengawas Obat Dan Makanan Nomor 31 Tahun 2018 tentang label pangan olahan meliputi nama produk: daftar bahan yang digunakan: berat bersih atau isi bersih; nama dan alamat pihak yang memproduksi atau mengimpor; halal bagi yang dipersyaratkan; tanggal dan kode produksi; keterangan kedaluwarsa; nomor izin edar; dan asal usul bahan Pangan tertentu. Oleh karena itu para tenant dalam membuat kemasan akan mengacu pada peratuan label pangan yang berlaku (Gambar 3).

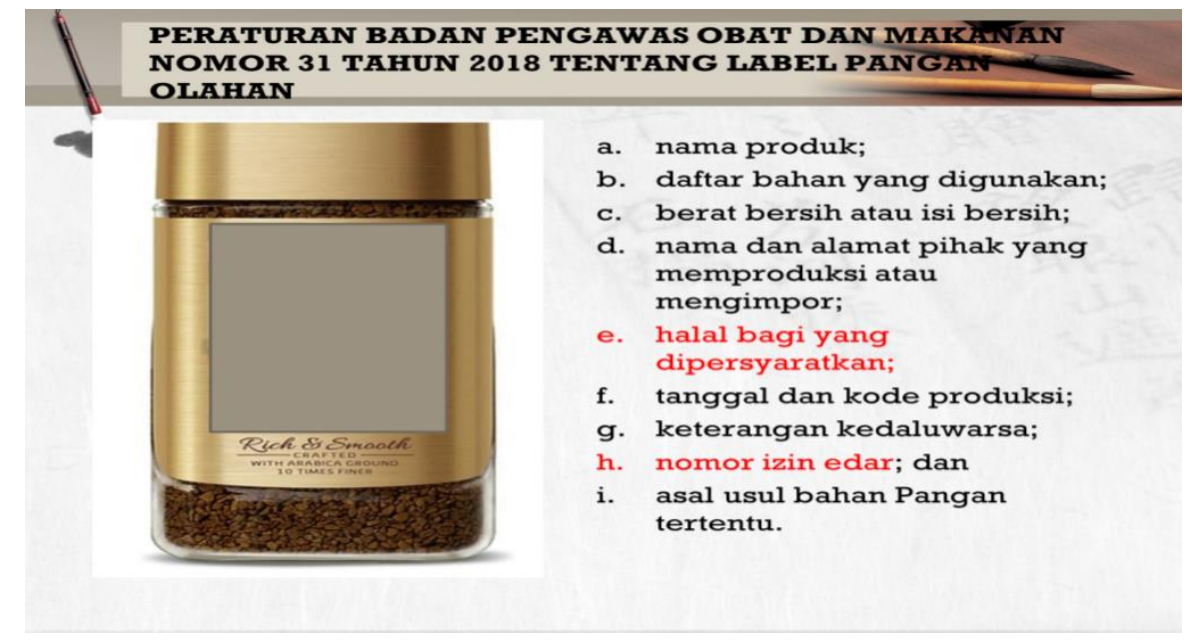

Gambar 3 Peraturan Badan Pengawas Obat dan Makanan tentang label pangan olahan

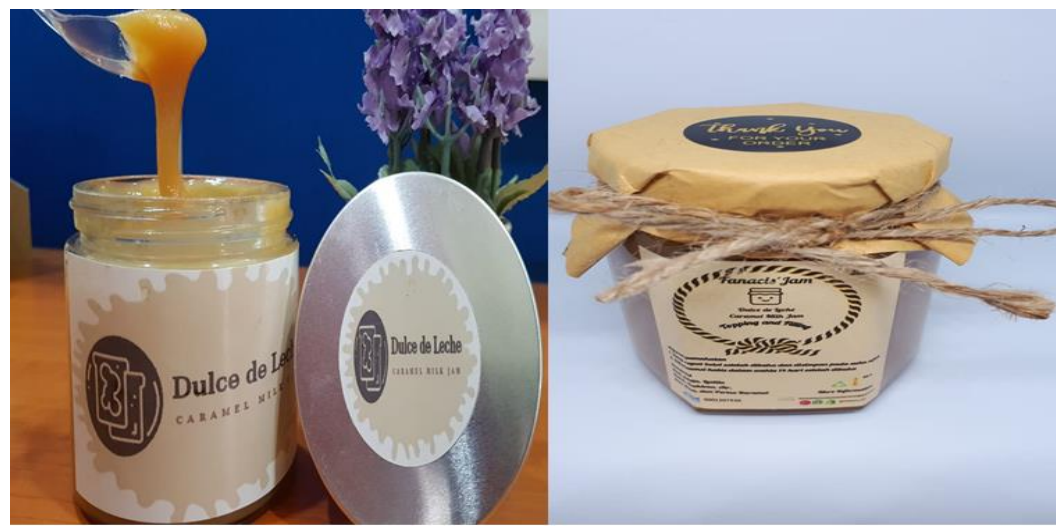

Gambar 4 Kemasan produk selai caramel sebelum dan setelah pendampingan

Program pendampingan menghasilkan perubahan atau perbaikan dari kemasan yang digunakan oleh beberapa tenant diantaranya fanacis jam dan roti karkus. Produk fanacis jam berupa produk selai karamel. Produk ini mengalami perubahan merk pada label. Awalnya kemasan memiliki merk produk Dulce de lache namun menjadi Fanacis jam yang memiliki arti susu karamel. Penamaan yang lebih sederhana dengan tujuan agar konsumen mudah dalam mengingat nama produk tersebut (Gambar 4). Selain itu pada kemasan yang baru telah mengikuti peraturan BPOM Nomor 31 Tahun 2018 sehingga telah mencantumkan informasi utama yang dibutuhkan 
oleh konsumen. Pemilihan warna cream pada kemasan untuk menunjukkan bahwa produk berupa selai karamel. Menurut Hidayat (2020) Warna yang digunakan dalam kemasan produk makanan harus benar-benar menunjukkan rasa produk itu sendiri.
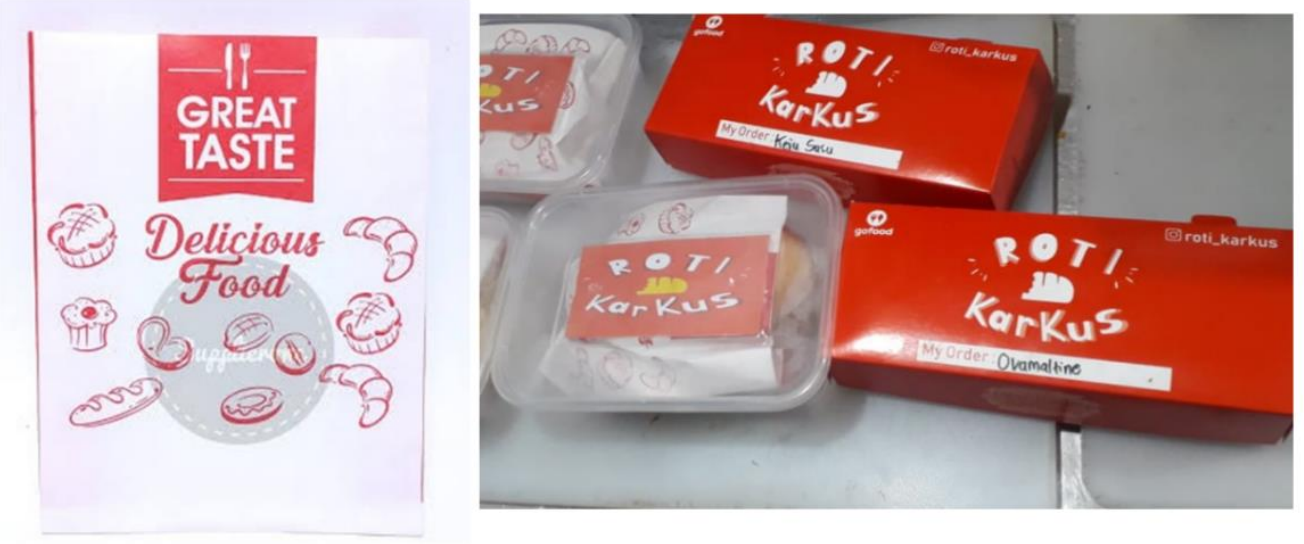

Gambar 5. Kemasan tenant Roti Karkus Setelah Mengikuti Pelatihan Kemasan

Produk roti karkus yang merupakan makanan siap santap mengalami perubahan desain pada kemasan. Sebelumn pendampingan menggunakan kemasan kertas yang ada dipasaran berupa kemasan kertas untuk mengemas roti menjadi kemasan karton atau plastik microwave dengan nama produk roti karkus (Gambar 5). Pemilihan warna dasar merah pada roti karkus karena warna merah dipercaya dapat memberikan efek penambah nafsu makan. Selian itu warna merah identik dengan semangat, antusias dan energi (Monica, 2011).

\section{KESIMPULAN}

Kegiatan pendampingan ini memberikan manfaat bagi para tenant. Sebanyak 12 tenant yang mengikuti kegiatan ini, sekitar $80 \%$ tenat mengalami perubahan tekait kemasan baik berupa desain maupun informasi yang diperlukan pada kemasan.

\section{UCAPAN TERIMA KASIH}

Terima kasih kepada Direktorat Riset dan Pengabdian Masyarakat Kementerian Riset dan Teknologi/Badan Riset dan Inovasi melalui Hibah Program Pengembangan Kewirausahaan yang telah mendanai kegiatan ini dan Universitas Trilogi yang telah menyediakan sarana dan prasarana mendukung kegiatan ini.

\section{DAFTAR PUSTAKA}

Hidayat, K. S. (2020). Pentingnya peran psikologi warna dalam bisnis kuliner. https://www.jurnal.id/id/blog/peran-psikologi-warna-dalam-bisnis-kuliner/

Jesslyn, B. N., \& Loisa, R. (2019). Pengaruh e-WOM di instagram terhadap loyalitas pelanggan kopi Janji Jiwa. Prologia, 3(2), 440-447.

Kodir, A., Islam, M. A., Pradana, G. W., Kusumaningrum, T. M., \& Rozaq, K. (2020). Pendampingan penyusunan standard operational procedure (SOP) dan desain kemasan bagi IKM makanan di Kabupaten Kediri dan Kota Batu. Abimanyu: Journal of Community Engagement, 1(1), 1-9.

Maulidian, M., Sumiasih, I. H., Puspitawati, M. D., \& Indrawan, I. (2019). Pola seleksi 
berdasarkan minat dan bakat pada calon tenant wirausaha Fakultas Bioindustri Universitas Trilogi. Abdihaz: Jurnal Ilmiah Pengabdian pada Masyarakat, 1(2), 45-52.

Monica, M., \& Luzar, L. C. (2011). Efek warna dalam dunia desain dan periklanan. Humaniora, 2(2), 1084-1096.

Mukhtar, S., \& Nurif, M. (2015). Peranan packaging dalam meningkatkan hasil produksi terhadap konsumen. Jurnal sosial humaniora (JSH), 8(2), 181-191.

Ningsih, F., Nas, S., \& Syabrus, H. (2015). Pengaruh kualitas produk dan harga terhadap keputusan pembelian air minum dalam kemasan (AMDK) merek aqua (studi pada mahasiswa Program Studi Pendidikan Ekonomi Universitas Riau) [Disertasi]. Universitas Riau

Nugrahani, R. (2015). Peran desain grafis pada label dan kemasan produk makanan UMKM. Imajinasi: Jurnal Seni, 9(2), 127-136.

Peraturan Badan Pengawasan Obat dan Makanan Nomor 31 Tahun 2018 Tentang Label Pangan Olahan (Berita Negara Republik Indonesia Tahun 2018 Nomor 1452)

Pulungan, M. H., Hastari, L. D., \& Dewi, I. A. (2019). Perbaikan desain kemasan produk biskuit brownies menggunakan metode quality function deployment (QFD). Teknotan: Jurnal Industri Teknologi Pertanian, 13(2), 39-46. 